\title{
AS RELAÇÕES BRASIL-ÁFRICA NO REGIME MILITAR E NA ATUALIDADE
}

\section{Africa-Brazil Relations During the Military Regime and in the Present-Day}

Bruno Gonçalves Rosi ${ }^{1}$

\section{INTRODUÇÃO}

Ao longo do governo Lula da Silva, o continente africano tornou-se um importante eixo da política externa brasileira, fato reconhecido por diversos analistas, veiculado por alguns dos principais veículos de comunicação do Brasil e mesmo explicitado pelo Itamaraty.

O objetivo deste texto é fazer uma breve análise histórica das relações BrasilÁfrica, focando em dois momentos: a política africana dos governos militares e a política africana dos governos democráticos, de Sarney até Lula, focando especialmente neste último.

O texto se divide em quatro seções, além desta introdução e da conclusão: na primeira seção, alguns dados básicos a respeito do continente africano e das relações Brasil-África são apresentados. Na segunda seção, é avaliada a política africana dos governos militares, dividindo-a em dois momentos: de Castelo Branco a Médici e de Médici a Figueiredo. Na terceira seção é avaliada a política africana dos governos democráticos, primeiro de Sarney a Fernando Henrique Cardoso e depois do governo Lula da Silva. Em seguida, a quarta e última seção faz um balanço, comparando primeiro as políticas de Lula e Geisel e depois analisando os prós e os contras da política africana de Lula da Silva. Na conclusão os principais pontos são resumidos e comentados.

\footnotetext{
1 Professor na Universidade Cândido Mendes, RJ, Mestre em Relações Internacionais (PUC/RJ) Graduado em História (UFF). bruno_rosi@ hotmail.com
} 


\section{Conjuntura Austral}

\section{DADOS BÁSICOS}

\subsection{CONTINENTE AFRICANO}

A África é o terceiro continente mais extenso do planeta, atrás da Ásia e da América, com cerca de 30 milhões de quilômetros quadrados (aproximadamente 20\% da área total da superfície terrestre, ou ainda, três vezes e meia o Brasil). Muitas formas de dividir essa ampla área para fins de estudo são utilizadas. Uma das mais tradicionais divide o continente em seis espaços: norte, centro, sul (ou austral/meridional), leste (ou oriental) e oeste (ou ocidental).

Segundo dados da ONU, a população do continente africano hoje é de aproximadamente 1 bilhão de pessoas. É um contingente, além de numeroso, heterogêneo: convivem no continente uma grande variedade de etnias, credos religiosos, línguas, culturas, opções políticas, etc.

Politicamente o continente africano encontra-se dividido em mais de 50 países total ou parcialmente reconhecidos pela comunidade internacional. Porém, parte significativa do continente consiste de Estados fracos, difusos e desagregados.

Ainda no campo político, é importante destacar a "desestrategização" do continente após a Guerra Fria. Até o início da década de 1990, o continente africano como outras áreas do mundo - era alvo de disputas por influência entre as grandes potências. Porém, com o ocaso da bipolaridade, grande parte do interesse ou atenção internacional desviou-se da região.

Economicamente, pouco avanço é observado no continente ao longo das décadas: dos 30 países com menor PIB per capita no mundo hoje, 26 são africanos. Em termos brutos, os países africanos competem com pequenas ilhas do Caribe e do Pacífico nas últimas posições dos rankings econômicos (dados do FMI e do BIRD). Sobretudo a partir da década de 1970, o continente passou por uma generalização do modelo econômico neoliberal. A opção não apenas não trouxe desenvolvimento, como também ampliou a dependência dos países africanos em relação aos países de fora do continente, ao esvaziar seu setor produtivo.

No domínio social o continente africano é marcado por crises e tragédias humanitárias, uma das mais significativas na atualidade, a epidemia HIV/AIDS. Desde 


\section{Conjuntura Austral}

o início do processo de descolonização, após a $2^{\mathrm{a}}$ Guerra Mundial, vários países africanos passaram por crises relacionadas a guerras civis, conflitos étnicos, deslocamento de refugiados, fome, doenças, etc. Dos 30 países com menor índice de desenvolvimento humano no mundo hoje, 28 são africanos (dados da ONU).

Outra informação relevante diz respeito à divisão do continente em blocos regionais: grande parte dos países africanos hoje se encontra agrupado em organizações deste tipo. A experiência africana nessa área é principalmente uma tentativa de emulação da experiência européia, procurando formas de contornar as dificuldades econômicas, políticas e sociais do continente. Alguns dos blocos mais relevantes da África hoje são: União Africana (UA); Comunidade Econômica dos Estados da África Ocidental (CEDEAO); Comunidade Econômica dos Estados da África Central (CEEAC); Autoridade Intergovernamental para o Desenvolvimento (Igad, África Oriental); Comunidade para o Desenvolvimento da África Austral (SADC); União do Maghreb Árabe (UMA).

\subsection{RELAÇÕES BRASIL-ÁFRICA}

Atualmente o Brasil possui embaixadas em 34 países africanos, ou seja, a maior parte dos países do continente. Metade delas foi aberta ou reaberta nos últimos oito anos.

Economicamente, a sinergia entre Brasil e África vem se acentuando ao longo dos anos. Dentre as principais empresas brasileiras de grande porte em atuação na África hoje podem ser destacadas aquelas relacionadas aos setores de infra-estrutura e energia: Andrade Gutierrez, Camargo Correia, Odebrecht e Petrobras. Podem ser mencionadas ainda outras empresas, como a Del Valle (alimentação), Vale do Rio Doce (mineração) e Banco do Brasil (finanças)

\section{3. ÁFRICA E GOVERNOS MILITARES}

Conforme destaca Letícia Pinheiro, a política externa do Brasil ao longo dos governos militares sofreu uma guinada da ideologia ao pragmatismo (PINHEIRO, 2004). Esse movimento também se fez sentir nas relações Brasil-África. Tendo isso em 


\section{Conjuntura Austral}

mente, dois grandes momentos podem ser observados nas relações entre o Brasil e o continente naquele período: o primeiro, de Castelo Branco até os últimos anos do governo Médici; o segundo, dos anos finais do governo Médici até a redemocratização, destacando-se os governos Geisel e Figueiredo.

\subsection{CASTELO BRANCO, COSTA E SILVA E MÉDICI}

Em âmbito geral, a política externa do Brasil no primeiro dos governos militares pode ser compreendida pela aplicação do binômio segurança e desenvolvimento, ou ainda, por um realinhamento fugaz ao bloco ocidental (RICÚPERO, 1995). A percepção dos tomadores de decisão, não necessariamente objetiva, era de um mapa mundial rigidamente dividido em dois blocos opostos, com a correspondente necessidade de clara adesão brasileira a um lado da bipolaridade. A política africana do Brasil não fugiu desta lógica.

Conforme pode ser observado a partir da análise de Vizentini, a política de Castelo Branco para a África assenta-se em um tripé: apoio ao colonialismo português, apoio a regime de segregação racial, ou Apharteid, sul-africano e confronto ao comunismo (VIZENTINI, 1998).

No entanto, aproveitando outro conceito do mesmo autor, esse é um tripé de geometrias variáveis: prevalece entre esses três fatores a percepção de que é tarefa do Brasil participar de um esforço internacional de luta contra o comunismo. Dentro dessa percepção encontram-se a imagem dos círculos concêntricos e a visão estratégica de defesa da fronteira leste, em direção ao Atlântico Sul e à África. É também em resposta a esta percepção que Castelo Branco apóia, mesmo que veladamente, o regime de segregação racial da África do Sul e promove encontros de chanceleres com Portugal, apoiando a política colonialista deste país.

Embora na diplomacia da prosperidade de Costa e Silva o alinhamento automático com os Estados Unidos sofra alguns reveses, o mesmo não pode ser dito a respeito da política inicial dos militares em relação ao continente africano. $\mathrm{O}$ apoio ao colonialismo português e ao Apharteid sul-africano, e, sobretudo o anticomunismo, 


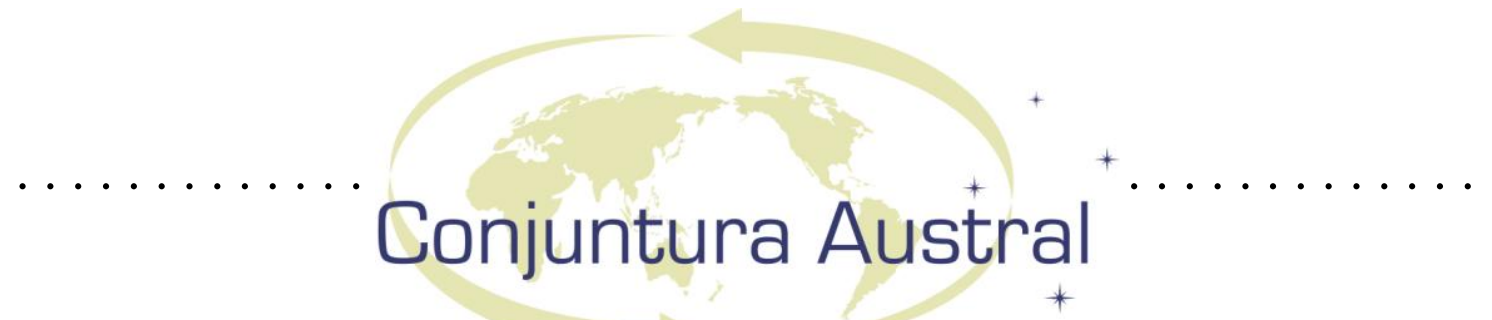

continuam sendo a lógica por trás da política brasileira para a região (VIZENTINI, 1998).

Conforme avançava o processo de descolonização, avançavam também as representações diplomáticas do país no continente: apenas em 1969, Costa do Marfim, Uganda, Zâmbia e Tanzânia. Nada, no entanto, que comprometesse as diretrizes básicas da política externa de Costa e Silva. Com a África do Sul, alguns eventos podem ser destacados: criação de uma linha aérea da South African Airways, ligando Rio de Janeiro e Johanesburgo; encontro de chanceleres dos dois países e a assinatura de um acordo financeiro, todos em 1969. Esses eventos demonstram que, embora o Brasil oficialmente não se solidarizasse com a segregação racial, na prática acabava por fortalecer política e economicamente a posição da minoria branca.

A política externa do governo Médici, pautada na diplomacia do interesse nacional, fortaleceu a posição do Brasil no bloco ocidental e retomou o americanismo, mas o fez de maneira pragmática, visando o projeto desenvolvimentista de Brasil Potência. Em relação à África, no entanto, apoio ao colonialismo português e ao Apharteid sul-africano - dentro da lógica de anticomunismo - continuaram sendo pilares básicos da política externa brasileira (GONÇALVES \& MIYAMOTO, 1993). Porém, os interesses econômicos e estratégicos do regime fizeram renascer o interesse brasileiro no continente (GONÇALVES \& MIYAMOTO, 1993).

É dentro dessa nova realidade que devemos entender o amplo programa ministerial de visitas, que entre 1972 e 1973 levou Mário Gibson Barbosa a dez países africanos: Senegal, Costa do Marfim, Gana, Togo, Daomé, Nigéria, Camarões, Gabão, Zaire (1972) e Quênia (1973).

Dentro da mesma lógica pode ser colocada a expansão do mar territorial brasileiro para 200 milhas náuticas. Embora questões petrolíferas e pesqueiras fossem apresentadas como justificativa à época, era claro que interesses estratégicos estavam por trás da empreitada da aproximar o Brasil da África pela mar. Essa aproximação, no entanto, enxergava o continente como ameaça, ameaça de um possível ataque comunista pelo Atlântico Sul. 


\section{Conjuntura Austral}

\subsection{GEISEL E FIGUEIREDO}

É com o governo Ernesto Geisel e seu pragmatismo responsável e ecumênico que o Brasil inicia em definitivo a retomada de aproximação com o continente africano durante os governos militares. É importante destacar que, dentro do pragmatismo vigente, essa aproximação se dá em moldes paradigmáticos bastante diversos dos governos anteriores. Além de representar uma ruptura com o passado, a diplomacia de Geisel torna centrais os aspectos políticos da aproximação com a África (GONÇALVES \& MIYAMOTO, 1993).

Um dos pontos a destacar na política africana de Geisel é a mudança de atitude em relação à África do Sul. Conforme já foi destacado, o apoio, mesmo que velado, ao regime de Pretória foi um dos pontos chave da política africana dos governos anteriores. Geisel rompe com essa lógica, e o Brasil passa a condenar publicamente o Apharteid.

Em segundo e terceiro lugar, o Brasil muda sua atitude em relação a Portugal e ao combate ao comunismo no continente africano. Talvez nada seja mais representativo desse novo momento do que o reconhecimento da independência de Angola, em 1975. Angola era uma ex-colônia portuguesa, o que por si só já representava o rompimento com o apoio ao colonialismo de Portugal. Mas essa não era uma situação inédita, o Brasil já havia reconhecido a independência de Guiné-Bissau, outra ex-colônia portuguesa. O que realmente chama a atenção é o fato de se reconhecer a independência de um novo Estado sob um governo socialista, no caso o MPLA. Mais ainda, o fato desse reconhecimento ser feito em oposição à política norte-americana, que manteve apoio à FNLA.

Dentro de sua política externa universalista, Figueiredo dá continuidade e aprofundamento aos planos de Geisel para a África (PEREIRA, 1985). Os interesses econômicos e estratégicos, e não a ideologia, respondem pela política africana deste governo (GONÇALVES \& MIYAMOTO, 1993).

Além do programa de visitas ministeriais (Saraiva Guerreiro visitou Moçambique, Angola, Tanzânia, Zâmbia e Zimbábue em 1980), inauguram-se também as visitas presidenciais a países africanos: em 1983, Figueiredo visita Nigéria, Senegal, Guiné-Bissau, Cabo Verde e Argélia. São as primeiras visitas de qualquer chefe de 


\section{Conjuntura Austral}

estado sul-americano ao continente. Em relação à África do Sul, a posição tomada por Geisel se acirra: em 1981 ocorre ameaça de intervenção militar brasileira favorável a Angola na região.

Examinando-se a política africana dos governos militares, pode-se observar um saldo bastante positivo, especialmente nos últimos dois governos: o número de embaixadas brasileiras no continente cresce de 12 (1974) para 21 (1984). O comércio bilateral cresce de US\$ 130 milhões (1970) para US\$ 3,3 bilhões (1985). Porém, como será visto, essa não foi a tendência dos anos seguintes.

\section{POLÍTICA EXTERNA BRASILEIRA NA ATUALIDADE}

Embora Mônica Hirst e Letícia Pinheiro tenham chegado a identificar uma retomada de política africana no governo de Itamar Franco (HIRST \& PINHEIRO, 1995), o período de Sarney a Fernando Henrique Cardoso é predominantemente marcado pela perda de interesse do Brasil pela África. Esse interesse seria retomado, no entanto, e com profundidade, no governo Lula da Silva.

\subsection{SARNEY, COLLOR, ITAMAR E FHC}

A crise de paradigmas da política externa brasileira foi acompanhada por uma profunda retração da política africana. Entre 1986 e 1989, Sarney fez uma visita a Cabo Verde (1986), propôs a conversão do Atlântico Sul em Zona de Paz e Cooperação (1986), recebeu em Brasília e condecorou Desmond Tutu por sua luta contra a segregação racial na África do Sul (1987) e propôs a criação do Instituto do Instituto Internacional da Língua Portuguesa (1989), algo que evoluiria para a mais robusta Comunidade dos Países de Língua Portuguesa (CPLP). É muito pouco, comparado com a tendência dos dois governos anteriores. Somado a isso, o fluxo comercial caiu.

Fernando Collor de Mello (1990-92), em sua autonomia pela participação, aprofundou essa retração. Além da quase inexistência de marcos políticos (Nelson Mandela visitou Brasília em 1991, mas isso foi um evento isolado), observou-se uma queda ainda mais profunda do comércio bilateral. 


\section{Conjuntura Austral}

Durante o breve governo Itamar Franco (1992-94), ainda sem um paradigma de política externa claramente definido (BUENO \& CERVO, 2002), o Brasil observou uma tênue retomada da política africana (HIRST \& PINHEIRO, 1995). Datam deste governo o lançamento da proposta de criação da CPLP (1993) e a insistência na criação da Zona de Cooperação do Atlântico Sul, esta última com importantes implicações para o relacionamento com a África do Sul. Também importante para o relacionamento com a África do Sul foi a aproximação com pares potenciais, países em nível de desenvolvimento semelhante ao do Brasil (China, Índia, Rússia e África do Sul), que evoluiria para ligações internacionais como o IBAS e os BRICs.

Outra marca da política externa de Itamar Franco traria conseqüências para o relacionamento com o continente africano: a integração, ainda que conservadora e reservada, a regimes e organismos internacionais. É nesta política que o Brasil participa de uma série de missões humanitárias no continente africano, a maioria através da ONU: Angola, Moçambique, África do Sul, Uganda, Ruanda e Libéria.

A tendência de retomada da política africana não se manteve no governo Fernando Henrique Cardoso (1995-2002). Em sua política externa de autonomia pela integração (LAMPREIA, 1998) ou institucionalismo pragmático (PINHEIRO, 2004), FHC voltou-se prioritariamente para os países desenvolvidos (EUA e UE) ou para a América do Sul (MERCOSUL). Em relação à África, houve uma frustração de expectativas (CERVO, 2002) ou perda relativa de atrativos (MOURÃO; CARDOSO \& ALTEMANI, 2006).

Presente no paradigma de política externa de FHC estava o abandono de divisões Leste-Oeste e Norte-Sul, o que serve como pano de fundo para essa mudança de atitude em relação à África. A cooperação Sul-Sul, que seria retomada com força por Lula da Silva, esteve ausente no governo FHC, por ser considerada anacrônica aos novos tempos. Em relação ao continente africano, além da continuação de programas de ajuda iniciados no governo anterior (e novos: apoio ao combate da epidemia HIV/AIDS no Senegal, 2002), observou-se a consolidação da CPLP em 1996 e uma visita presidencial à África do Sul no mesmo ano. Também em relação a este país, acordo de formação de área de livre comércio com o MERCOSUL (2000). 


\section{Conjuntura Austral}

\subsection{LULA}

É com Lula da Silva e sua autonomia pela diversificação (VIGEVANI \& CEPALUNI, 2007) que se observa uma reversão do quadro na política africana do Brasil (MOURÃO; CARDOSO \& ALTEMANI, 2006). Com a cooperação Sul-Sul, central no paradigma adotado, ocorre uma intensificação das relações com países emergentes (África do Sul entre eles, através do IBAS), além de retomada e estreitamento das relações com países africanos (VIGEVANI \& CEPALUNI, 2007).

Apenas em seu primeiro mandato, Lula visitou 14 países do continente. Ao longo de dois mandatos, o número chegou a mais de 20, alguns visitados em diferentes ocasiões, tornando Lula o presidente brasileiro que mais vezes visitou a África como chefe de Estado.

A presença diplomática do Brasil cresceu substancialmente nesse período: das 34 embaixadas brasileiras na África hoje, metade foi aberta ou reaberta nos últimos oito anos. Além de ampliar a presença política do país no continente, esse gesto facilitou o crescimento do comércio bilateral e da presença de empresas brasileiras em países africanos, como Petrobras, Vale e Odebrecht (Estado de S. Paulo, 4 de julho de 2010).

O comércio entre Brasil e os países africanos saltou de cerca de US\$ 5 bilhões em 2003 para US\$ 29 bilhões em 2009, tornando a África a quarta maior parceira comercial do Brasil. Em 2008, antes da crise, estes números correspondiam a 5,14\% das exportações do Brasil e a 9,11\% das importações (Revista Época, 7 de novembro de 2010). A responsabilidade pelo déficit recai sobre a compra de petróleo, especialmente da Nigéria, um quadro que possivelmente será mudado com a exploração do Pré-Sal.

Segundo o Itamaraty, além de aproximação cultural e política, o Brasil tem interesse em estreitar laços econômicos e comerciais com os países africanos, principalmente nas áreas de energia e mineração (Portal G1, 12 de outubro de 2007). O secretário de imprensa da Presidência, Carlos Villanova, destacou essa "renovada prioridade que a política externa brasileira concedeu ao continente africano" ao longo dos últimos oito anos em novembro de 2010, quando Lula fez sua última viagem à 


\section{Conjuntura Austral}

África como presidente do Brasil, visitando Moçambique (Revista Época, 7 de novembro de 2010).

Dos muitos gestos políticos do governo Lula em direção à África, alguns podem ser destacados: fortalecimento da CPLP e do IBAS; visita de diversos chefes de Estado ao Brasil a convite do presidente; cooperação econômica, social e cultural com diversos países (destacando-se Gana, Camarões, Guiné-Bissau, Nigéria, Moçambique e Angola); acordos econômicos MERCOSUL-SACU (União Aduaneira da África Austral) e do MERCOSUL com países da CPLP.

\section{BALANÇO FINAL}

\subsection{PEB GOVERNOS MILITARES VS. PEB GOVERNO LULA}

Muitas análises vêm sendo feitas destacando semelhanças entre a política externa atual e aquela do governo Geisel. De fato, como alguns autores vêm ressaltando, há no mínimo uma retomada de pontos do pragmatismo responsável e ecumênico de Geisel na política externa de Lula da Silva (CARDOZO \& MIYAMOTO, 2006). Esses pontos, aliás, já estavam presentes mesmo antes, na Política Externa Independente (PEI), de Jânio Quadros e João Goulart, e em menor medida na Operação PanAmericana (OPA) e outras medidas de política externa de Juscelino Kubitschek ((BUENO \& CERVO, 2002).

Embora autores falem a respeito de um "salto qualitativo dentro de uma mesmo matriz de idéias e visões de mundo" (LIMA \& HIRST, 2010), talvez o mais prudente seja balizar-se pela análise do próprio chanceler Celso Amorim, e afirmar que entre a PEI, o pragmatismo responsável e a autonomia pela diversificação há "pontos de contato (...) mas os problemas mudaram": uma vez que se trata de cenários domésticos e internacionais bastante diversos, qualquer analogia corre o risco de se tornar “simplificadora” (AMORIM, 2010).

É dentro dessa percepção que passo a uma análise dos prós e contras da política africana de Lula da Silva. 


\section{Conjuntura Austral}

\subsection{CRÍTICAS E VANTAGENS DAS RELAÇÕES BRASIL-ÁFRICA NA ATUALIDADE}

Dentre as críticas apresentadas à política africana de Lula da Silva, destaco quatro pontos: primeiro, a pouca relevância do comércio Brasil-África: em termos globais, conforme já observado neste texto, o comércio bilateral entre Brasil e África corresponde a uma porcentagem pequena do comércio internacional brasileiro, porcentagem essa que possivelmente não justifica os esforços da diplomacia na direção do continente africano.

Em segundo lugar, e ainda no campo do comércio, observa-se um déficit comercial do Brasil em relação à África; em terceiro lugar, ao privilegiar a África, o Brasil exclui áreas de comércio mais relevantes, com os Estados Unidos e a UE. Finalmente, as críticas muitas vezes apontam para a existência de uma equivocada dicotomia norte/sul por trás da atual política externa brasileira. Argumentos análogos a este último falam sobre "esquerdismo" ou "terceiro mundismo".

A cada uma dessas críticas, argumentos favoráveis podem ser alocados: em relação a pouca relevância comercial, o Itamaraty responde com o argumento de que mercados precisam de tempo de maturação. De fato, quando se analisa o fortalecimento do comércio ao longo dos últimos oito anos, pode-se concluir que a tendência é de crescimento. Pode-se também argumentar favoravelmente observando a relativa desatenção internacional para a África: trata-se de um mercado relativamente esquecido e de grande potencial.

A respeito do déficit comercial, já foi argumentado que uma análise mais aprofundada revela na verdade um superávit quando se desconta o petróleo das contas. Uma análise mais aprofundada e específica precisaria ser feita para que o impacto da entrada do Pré-Sal nessa conta revela-se seus efeitos em potencial.

Quanto às áreas de comércio, o Itamaraty alerta para a existência de complementação, e não exclusão. Não se trata de abandonar os mercados da Europa, Estados Unidos ou outros, mas sim de diversificar possibilidades.

No campo da política internacional, argumentos favoráveis podem ser feitos a respeito da existência de um universalismo na atual política externa, não de um 


\section{Conjuntura Austral}

privilégio para regiões ou matizes político-ideologicas. Há que se argumentar também que, na medida em que a busca por maior relevância se constitui como objetivo para a política externa do Brasil, a busca por um número amplo e variado de parcerias se faz importante.

Contudo, um último ponto pode ser avançado: em sua política externa universalista, o atual governo recebe inúmeras críticas e acusações no campo da defesa de direitos humanos, o que também se aplica ao caso africano.

De fato, na medida em que o pragmatismo se torna elemento central da política externa, e a defesa dos interesses nacionais objetivo primordial, espera-se uma relatividade ideológica (ou esvaziamento). Não se pode negar, no entanto, que essa prática se encaixa em uma lógica coerente: em diferentes ocasiões o ministro Celso Amorim reiterou sua opinião de que mudanças são mais fáceis pela aproximação, e não isolamento. A validade ou não deste argumento, logicamente, só poderá ser perfeitamente avaliada no futuro.

Há que se apontar também outro lado desta questão: ao se aproximar de governos africanos de forma pragmática, ignorando as normas dos direitos humanos, o governo brasileiro recebe inúmeras críticas de grandes veículos de comunicação, e corre o risco de perder popularidade, pelo menos entre uma parcela especifica e informada da população. Corre também o risco de ser comparado às grandes potências em suas práticas imperialistas, pretensa hegemonia e unilateralismo, práticas tão criticadas por Celso Amorim e pelo Itamaraty de modo geral.

\section{CONCLUSÃO}

Ao longo dos governos militares, a África vagarosamente tornou-se uma área de grande interesse para a política externa brasileira. Embora os governos Castelo Branco e Costa e Silva pouca atenção tenham dado ao continente, principalmente se comparados com a PEI anterior, a partir do governo Médici, e principalmente nos governos Geisel e Figueiredo, a África volta a adquirir importância. 


\section{Conjuntura Austral}

Com a redemocratização, a África volta a perder importância na política externa brasileira. Apesar de uma breve retomada no governo Itamar Franco, essa importância só volta a ser plenamente adquirida no governo Lula da Silva.

Embora semelhanças gerais possam ser apontadas entre as políticas externas de Geisel e Lula, análises a respeito destes dois governos devem levar em consideração fatores como as mudanças políticas internas e as mudanças do cenário internacional entre os dois períodos. Esta observação é válida também para as políticas africanas destes dois governos.

De modo geral, as objeções à atual política africana, veiculadas por diversos veículos midiáticos, podem ser satisfatoriamente respondidas por argumentos favoráveis do Itamaraty e de outros analistas. Porém, ao escolher o pragmatismo como regra de ação, o Itamaraty pode estar deixando de contribuir para o desenvolvimento de importantes regimes internacionais, como a defesa dos direitos humanos, e correndo o risco de tornar o Brasil em um Estado imperialista, esvaziando inclusive grande parte do discurso atual da PEB.

\section{REFERÊNCIAS:}

ALTEMANI, Henrique. Política Externa Brasileira. São Paulo: Saraiva, 2005.

BUENO, C. \& CERVO, A . História da Política Exterior do Brasil. 2. Ed. Brasília: Editora Universidade de Brasília, 2002.

CARDOZO, Sandra Aparecida; MIYAMOTO, Shiguenoli. "Política externa brasileira em dois momentos: uma análise comparativa entre a política externa do governo Geisel e do governo Lula". Trabalho apresentado no 5o Encontro da Associação Brasileira de Ciência Política (ABCP), UFMG, Belo Horizonte, 2629 jul. 2006. Folha de S. Paulo. Domingo, 14 de Novembro de 2010

GONÇALVES, Williams e MIYAMOTO, Shiguenoli. "Os militares na Política Externa Brasileira, 1964-1984”. Estudos Históricos, vol.6, n.12, 1993. 


\section{Conjuntura Austral}

HIRST, Monica e PINHEIRO, Leticia. "A Política Externa do Brasil em dois tempos". Revista Brasileira de Política Internacional, Ano 38, n 1, p. 5-23 [1995].

LAMPREIA, L.F. "A Política Externa do Governo FHC: continuidade e renovação". Revista Brasileira de Política Internacional, v. 41, n. 2. , 1999.

MOURÃO, Fernando Augusto. "O Brasil e a África". In: FONSECA JR., G. \& CASTRO, Sérgio Henrique (org.). Temas de Política Externa Brasileira II. Rio de Janeiro: Paz e Terra, 1997.

, Fernando Augusto; CARDOSO, Fernando Jorge; ALTEMANI, Henrique. "As relações Brasil-África: de 1990 a 2005". In: ALTEMANI, Henrique \& LESSA, Antônio Carlos (Orgs.). Relações Internacionais do Brasil: Temas e Agendas, v. 1. São Paulo: Saraiva, 2006.

PINHEIRO, Letícia. Política Externa Brasileira (1889-2002). Rio de Janeiro: Jorge Zahar Ed., 2004.

RICÚPERO, Rubens. Visões do Brasil: Ensaios sobre a história e a inserção internacional do Brasil. São Paulo: Editora Record. 1995.

VIGEVANI, Tullo e CEPALUNI, Gabriel. "A Política Externa de Lula da Silva: a estratégia de autonomia pela diversificação". Contexto Internacional. Vol. 29, n. $02,2007$.

VIZENTINI, Paulo Fagundes. "O G-3 e o G-20: o Brasil e as novas coalizões internacionais”. In: ALTEMANI, Henrique \& LESSA, Antônio Carlos (Orgs.). Relações Internacionais do Brasil: Temas e Agendas, v. 2. São Paulo: Saraiva, 2006.

Paulo Fagundes. A política externa do regime militar brasileiro. Porto Alegre: UFRGS, 1998.

Paulo Fagundes. Relações Internacionais do Brasil: de Vargas a Lula. São Paulo: Fundação Perseu Abramo, 2002.

Estado de $\quad$ S. Paulo. Disponível em http://www.estadao.com.br/estadaodehoje/20100704/not_imp576027,0.php Acesso em 30 de Novembro de 2010.

Revista Época. Disponível em http://revistaepoca.globo.com/Revista/Epoca/0,EMI185744-15223,00.html Acesso em 30 de Novembro de 2010. 


\section{Conjuntura Austral}

Portal G1. Disponível em http://g1.globo.com/Noticias/Politica/0,,MUL1492375601,00-LULA+FAZ+VIAGEM+A+AFRICA+NO+MANDATO.html Acesso em 30 de Novembro de 2010.

Dados do FMI disponíveis em http://www.imf.org/external/index.htm Acesso em 30 de Novembro de 2010.

Dados do Banco Mundial. Disponíveis em http://siteresources.worldbank.org/DATASTATISTICS/Resources/GDP.pdf Acesso em 30 de Novembro de 2010.

Dados da ONU sobre desenvolvimento humano. Disponível em http://hdr.undp.org/en/statistics/ Acesso em 30 de Novembro de 2010. 


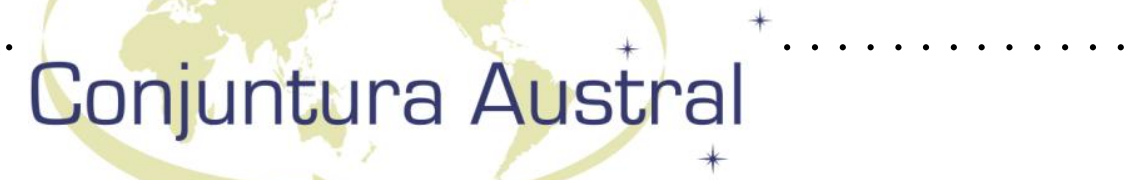

\title{
RESUMO
}

Este artigo analisa as relações politico-comerciais Brasil-África em dois momentos, o regime militar e a atualidade, procurando analisar brevemente ambos e explorar pontos de contato e perspectivas atuais da política africana.

\section{PALAVRAS-CHAVE}

Governos militares; Governo Lula; Política africana

\begin{abstract}
This article examines the political and commercial relations between Brazil and Africa on two periods, the military regime and the present, aiming to briefly examine both and explore points of contact and current perspectives of the African policy.
\end{abstract}

\section{KEYWORDS}

Military Governments; Lula’s Government; African Policy. 